\title{
The Medicalization of Suicide
}

\section{Louis Ruffalo*}

Psychoanalytic Psychotherapist, New Bern, North Carolina, USA

*Corresponding author: M. Louis Ruffalo, Psychoanalytic Psychotherapist, New Bern, North Carolina, USA, Tel: 4129164014; E-mail: mIruffalo@gmail.com

Received Date: September 24, 2014, Accepted Date: September 25, 2014, Published Date: September 30, 2014

Copyright: @ 2014, M. Louis Ruffalo, This is an open-access article distributed under the terms of the Creative Commons Attribution License, which permits unrestricted use, distribution, and reproduction in any medium, provided the original author and source are credited.

\section{Editorial}

The recent death of actor and comedian Robin Williams has propelled into the national consciousness a discussion of suicide, depression, and mental health, with professionals and nonprofessionals alike weighing in on these important issues. Unfortunately, there has been a great deal of misinformation disseminated, particularly on the relationship between suicide and mental illness.

Since the passing of Williams, countless articles and news reports have stated as fact the claim that suicide, i.e., voluntary death, is always the result of depression or other mental illness. The origin of this claim certainly predates William's death, but the suicide of the well-known celebrity has led it to be repeated ad nauseam by reporters, journalists, and mental health professionals alike. The only problem with the claim that suicide is always caused by mental illness is that it is untrue, and a careful examination of the subject reveals its patent falsity [1].

In sociology, medicalization refers to the misclassification of nonmedical problems as medical conditions. A great deal has been written on medicalization as it pertains to psychiatry in wake of the recent publication of DSM-5. Allen Frances is a prominent psychiatrist who in particular has warned of the expanding boundaries of psychiatry and the growing tendency to treat all forms of human suffering as symptoms of underlying mental disorder. Suicide, like other human problems, has itself fallen victim to medicalization as a consequence of the much broader social trend of treating all human problems as medical or psychiatric ones.

Pridmore is a psychiatrist who outlines that suicide is medicalized when it is considered a medical diagnosis, per se, when it is considered to be secondary to a mental disorder when no mental disorder is present, and when no mental disorder is present but the management of suicidal behavior is believed to be the sole responsibility of mental health professionals. The medicalization of suicide is not without consequence: it distorts our understanding of suicide, leads to the dissemination of false information about suicide, and contributes further to the stigma surrounding suicide and mental illness.
Clinical experience and common sense alike indicate that suicide is not universally the result of mental illness, and it most certainly is not a mental illness itself. Certainly, there are people who are mentally ill who commit suicide. In my experience, this is usually the case. However, there can be no doubt that there are individuals who commit or attempt suicide who are not mentally ill. These are people who perhaps are enduring great physical pain, have experienced major life stress, or have simply decided that they would like to die on their own terms rather than face the unknown prospect of slow, painful, or untimely death.

Instead of repeating the thoughtless claim that suicide is always caused by mental illness, it's time we start thinking critically and realistically about the topic that Camus called the only "truly serious philosophical problem." Suicide is the most personal of all human decisions and the ultimate self-determined action, one that can be fully informed and made by a person who has embraced the finite nature of his existence and has chosen voluntary death by his own hand.

The great German philosopher Arthur Schopenhauer proclaimed, "There is nothing in the world to which every man has a more unassailable title than to his own life and person." Suicide is an inherently moral and philosophical issue, a topic that reaches far beyond the field of mental health, despite the fact that we have resorted to strictly psychiatric terms to describe it.

M. Louis Ruffalo, M.S.W., is a psychoanalytic psychotherapist in practice in New Bern, North Carolina. He serves on staff at Carolina East Medical Center in New Bern, has a solo private practice of psychotherapy, and is an adjunct faculty member in psychiatry at the University of North Carolina.

\section{References}

1. Pridmore S (2011) Medicalisation of suicide. Malaysian Journal of Medical Sciences 18: 78-83. 